\title{
latrogenic Supravalvular Aortic Stenosis
}

\author{
Paolo Bosco, MD*, Antonella Ferrara, MD, Samer A. M. Nashef, MB, ChB, FRCS, PhD \\ Department of Cardiothoracic Surgery, Papworth Hospital, Papworth Everard, Cambridgeshire, UK
}

\begin{abstract}
We describe a case of hemolytic anemia and proximal anastomotic site stenosis following emergency repair of a Type A aortic dissection. This rare complication led to a reoperation to correct the iatrogenic aortic stenosis and cure the consequent hemolysis. A "sandwich" technique (with two Teflon strips on the outside and inside of the aortic wall) was used in the initial repair to reinforce the suture line and prevent bleeding from the aortic anastomoses. At the time of reoperation, the inner Teflon strip at the proximal aortic anastomosis was found to have inverted into the aortic lumen, as suggested by the preoperative magnetic resonance imaging. Surgical treatment consisted of resecting the portion of inner Teflon that had turned in and tacking the remaining part back onto the aortic wall. The observed hemolysis was likely due to the turbulent flow associated with the supra-aortic stenosis and the collision of red cells with the internal Teflon strip. The patient made an uncomplicated recovery with no further hemolysis and was discharged on postoperative day 8.

Copyright @ 2016 Science International Corp.
\end{abstract}

\section{Key Words:}

Aortic dissection - Hemolysis - Teflon strip • Sandwich technique

\section{Introduction}

Type A aortic dissection represents a true surgical emergency. As a consequence of the progress in aortic surgery developed in the last two decades, including surgical, brain protection, and perfusion techniques [1, 2], morbidity and mortality related to this condition have improved but remain substantial [3]. We report a case of successful treatment of hemolytic anemia and severe stenosis of the proximal aortic anastomosis resulting from the surgical repair of acute Type A aortic dissection.

\section{Case Presentation}

A 64-year-old female was admitted to our hospital with Type A aortic dissection. She underwent emergency ascending and proximal arch replacement using a 32-mm Hemashield graft. Bypass was via right axillo-atrial cannulation. The ascending aorta was excised, and the proximal edge sandwiched between two layers of Teflon. The proximal anastomosis was then completed with continuous 3-0 Prolene. Under deep hypothermic circulatory arrest with unilateral cerebral perfusion via the right axillary artery, the distal anastomosis was completed using a sandwich technique similar to the proximal anastomosis with two layers of Teflon and a running 3-0 Prolene stitch. Bypass was easily discontinued without inotropes. The patient was discharged to the ward in stable condition on postoperative day 2. Her hemoglobin level was $103 \mathrm{~g} / \mathrm{L}$. In the following week, we observed progressive anemization, which eventually led to transfusion on postoperative day 8 when her hemoglobin was as low as $72 \mathrm{~g} / \mathrm{L}$. On examination there was evidence of systolic murmur of Levine III/ $\mathrm{VI}$ at the right sternal border of the second intercos-

\footnotetext{
* Corresponding Author:

Paolo Bosco, MD

Department of Cardiothoracic Surgery

Papworth Hospital

Cambridge CB3 8RE, UK

Tel.: +44 1480 830541, Fax: +44 1480 364744, E-Mail: P.Bosco@nhs.net
} 
tal space and no other abnormal findings. Hemolysis was suspected and eventually confirmed on blood film, which showed occasional schistocytes with helmet cells, slight rouleaux formation, and mild uniform thrombocytosis. Hemolysis markers were raised (lactate dehydrogenase 2,018 U/L; bilirubin $23 \mu \mathrm{mol} / \mathrm{L}$ ). Echocardiography showed no valve lesion, while the ascending aorta was not well visualized. Computed tomography (CT) was nondiagnostic. Magnetic resonance imaging (MRI) consisting of steady-state free precession cine images were acquired on a Siemens Avanto 1.5T MRI system using a 32-channel surface coil. They revealed a high velocity central jet at the level of the proximal graft anastomosis with the residual orifice measuring approximately $8 \mathrm{~mm}$ in diameter and a significant degree of turbulence across the stenosis, with a peak gradient to $67 \mathrm{mmHg}$ (Figures 1 and 2).

The only conceivable explanation was that the proximal edge of the internal strip of Teflon had been lifted into the center of the aortic lumen by the blood flow. During revision surgery, the graft was opened immediately distal to the anastomosis, and redun-

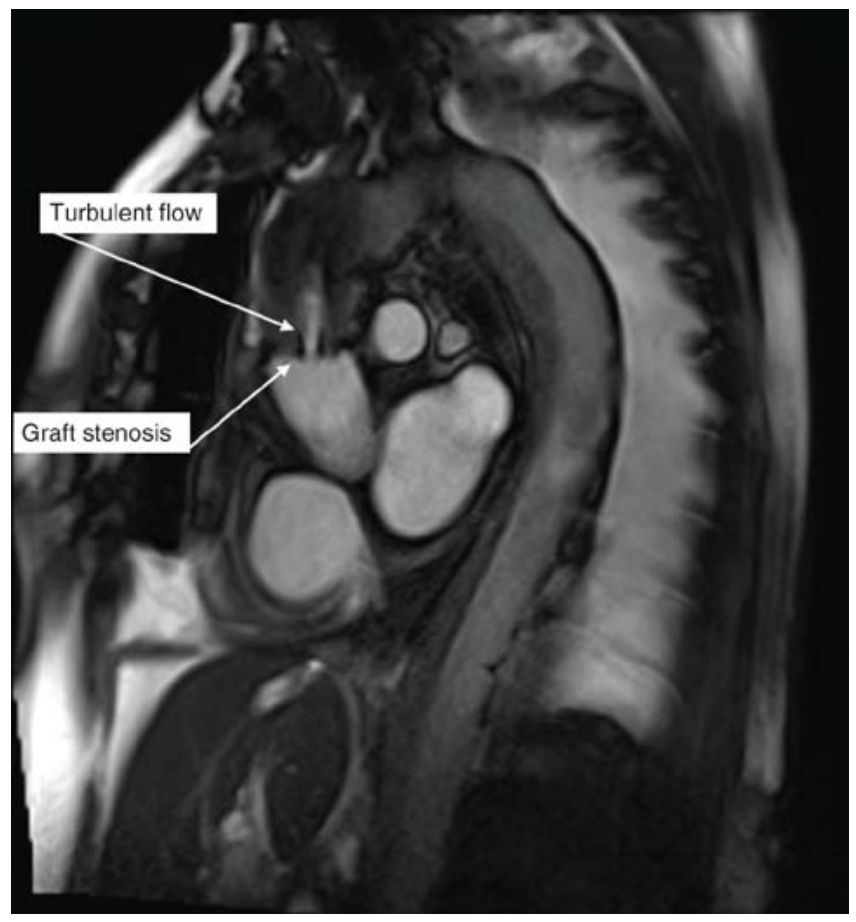

Figure 1. Lateral view of the magnetic resonance imaging scans showing turbulent flow across the stenotic proximal anastomosis and true and false lumen in the arch and descending aorta. dant Teflon was partly trimmed and partly tacked back onto the aortic wall with 4-0 Prolene sutures (Figures 3 and 4). The patient made an uncomplicated recovery with no further hemolysis and was discharged on postoperative day 8 . She remained well at follow-up 10 weeks later, and blood tests showed normal hemoglobin $(116 \mathrm{~g} / \mathrm{dL})$.

\section{Discussion}

Hemolytic anemia and stenosis of the anastomotic site are extremely rare complications, and there are few reports describing this unfortunate event [4-8].

The main cause appears to be the inverted and stiffened internal felt strip. The use of an internal felt strip as part of the sandwich technique for the treatment of Type A aortic dissection is not unusual. The aim of this approach is to reinforce the fragile, dissected aortic wall and prevent or minimize bleeding from the anastomotic site.

The risk of complications such as clot formation, hemolysis, and stenosis of the anastomotic site should be therefore carefully considered and bal-

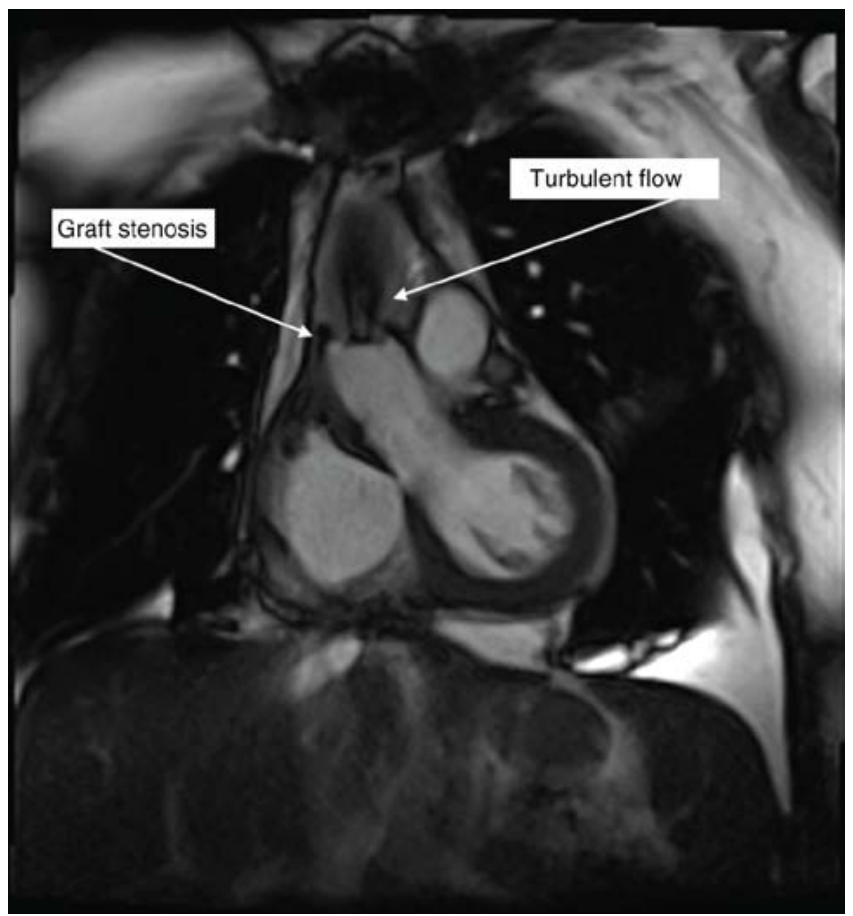

Figure 2. Frontal view showing the same pathologic feature of turbulent flow. 


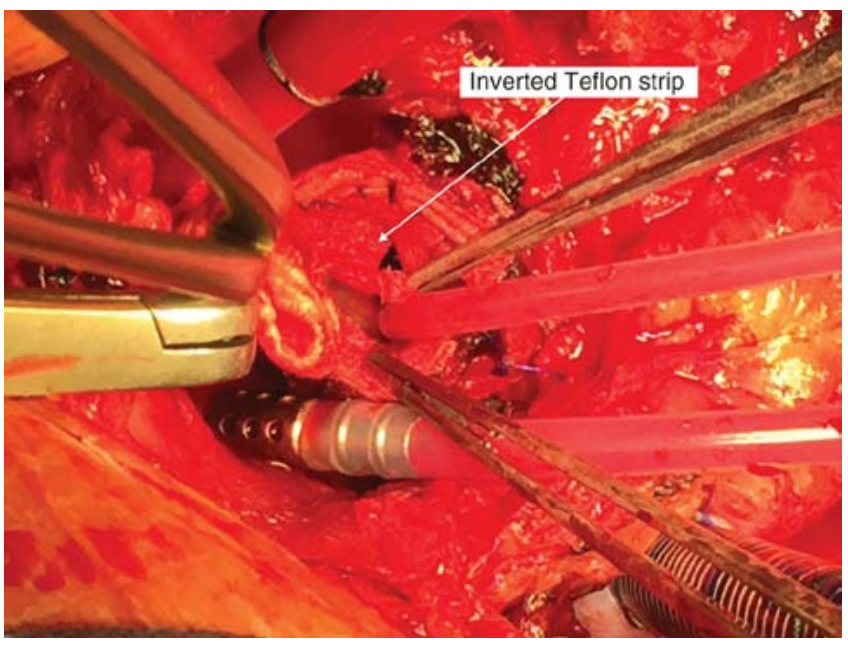

Figure 3. Graft opened, before refashioning.

anced with the benefits provided by this technique. To minimize risk, the strip should be narrow, and the sutures should be passed as close as possible to its proximal edge. The presence of a systolic murmur on examination and laboratory evidence of hemolysis should raise suspicion of this rare complication. Further imaging including echocardiography, CT, and/or MRI is mandatory to confirm the diagnosis and plan a surgical correction.

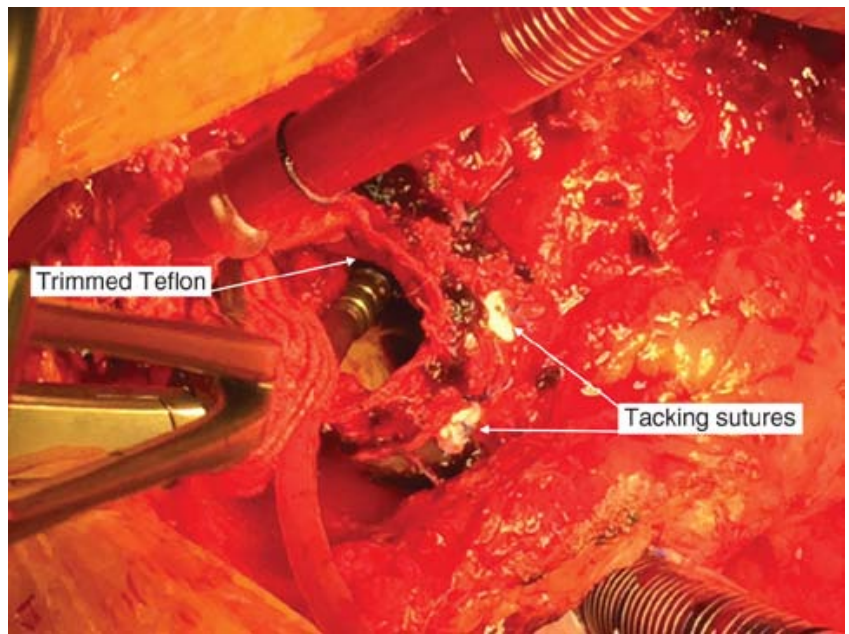

Figure 4. After refashioning, the aortic lumen is clearly patent with a visibly larger diameter.

\section{Acknowledgement}

We thank Bobby Agrawal for his contribution to the diagnosis of this case.

\section{Conflict of Interest}

The authors have no conflict of interest relevant to this publication.

\section{Comment on this Article or Ask a Question}

\section{References}

1. Ren Z, Wang Z, Hu R, Wu H, Deng H, Zhou $Z$, et al. Which cannulation (axillary cannulation or femoral cannulation) is better for acute type A aortic dissection repair? A meta-analysis of nine clinical studies. Eur J Cardio-Thoracic Surg. 2015;47:408-415. DOI: 10.1093/ejcts/ezu268

2. Comas GM, Leshnower BG, Halkos ME, Thourani VH, Puskas JD, Guyton RA, et al. Acute Type A dissection: impact of antegrade cerebral perfusion under moderate hypothermia. Ann Thorac Surg. 2013;96:2135-2141. DOI: 10.1016/j.athoracsur.2013.06.085

3. Conway BD, Stamou SC, Kouchoukos NT, Lobdell KW, Khabbaz KR, Murphy E, et al. Improved clinical outcomes and survival following repair of acute type $A$ aortic dissection in the current era. Interact Cardio- vasc Thorac Surg. 2014;19:971-976. DOI: 10.1093/icvts/ivu268

4. Hata M, Yoshitake I, Wakui S, Unosawa S, Hata $\mathrm{H}$, Shiono M. Postoperative early hemolytic anemia due to inverted teflon felt strip after emergency repair for type A dissection. Thorac Cardiovasc Surg. 2012;60:482-484. DOI: 10.1055/s-0031-1280006

5. Nakamura $\mathrm{Y}$, Ogino $\mathrm{H}$, Matsuda $\mathrm{H}$, Minatoya K, Sasaki H, Kitamura S. Hemolytic anemia after operation for aortic dissection using teflon felt strips. Ann Thorac Surg. 2008;85:1784-1787. DOI: 10.1016/j. athoracsur.2007.11.057

6. Matsuura K, Ogino H, Minatoya K, Sasaki H. Aortic stenosis caused by the felt strip used in repair for acute aortic dissection. Interact Cardiovasc Thorac Surg. 2004;3:41-43. DOI: 10.1016/S1569-9293(03)00217-2
7. Shingu Y, Aoki H, Ebuoka N, Eya K, Takigami $\mathrm{K}$, Oba J, et al. A surgical case for hemolytic anemia after ascending and total arch replacement. Ann Thorac Cardiovasc Surg. 2005;11:416-418. PMID: 16401994

8. Sekine $Y$, Yamamoto S, Fujikawa T, Oshima $S$, Ono M, Sasaguri S. Haemolytic anaemia resulting from the surgical repair of acute type A aortic dissection. Interact Cardiovasc Thorac Surg. 2014;18:230-233. DOI: 10.1093/icvts/ivt481

Cite this article as: Bosco P, Ferrara A, Nashef SAM. latrogenic Supravalvular Aortic Stenosis. AORTA (Stamford). 2016;4(5):172-174. DOI: http://dx.doi. org/10.12945/j.aorta.2016.16.008 